\title{
Pleural Lymphoma
}

National Cancer Institute

\section{Source}

National Cancer Institute. Pleural Lymphoma. NCI Thesaurus. Code C45687.

A rare extranodal lymphoma that arises from the pleura with no evidence of involvement

of other sites at the time of diagnosis. This category includes primary effusion

lymphoma and pyothorax-associated lymphoma. 